\title{
Prevalence of urinary schistosomiasis schoolchildren in White Nile State, Sudan
}

\author{
Hind A. Elsiddig ${ }^{1}$, Elham Khider ${ }^{2}$, Saada M. Nour ${ }^{3}$, Abdelrafie M. Makhawi ${ }^{5}$ and Mogadam B. \\ E. Mogadam ${ }^{4 *}$ \\ ${ }^{1}$ Department of Pathology, College of Medicine, University of Bahri, Khartoum, Sudan. \\ ${ }^{2}$ Ministry of Health, Khartoum State, Khartoum, Sudan. \\ ${ }^{3}$ Department of Microbiology, College of Medicine, University of Bahri, Khartoum, Sudan. \\ ${ }^{4}$ Department of Microbiology, Faculty of Medical Laboratory Sciences, University of Medical Sciences and Technology, \\ Khartoum, Sudan. \\ ${ }^{5}$ Department of Biotechnology, College of Applied and Industrial, Sciences, University of Bahri, Khartoum, Sudan.
}

Accepted 10 January, 2019

\begin{abstract}
Urinary schistosomiasis is endemic in sub-Saharan Africa, including Sudan, the risk for schistosomiasis is widespread, especially in the major irrigation systems in the Gezira area between the Blue and White Nile Rivers and both Schistosoma mansoni and Schistosoma hematobium are endemic. A cross sectional descriptive study was done to determine the prevalence of urinary schistosomiasis. Randomly 385 children were selected (223 males, 162 females) from the total population of three basic mixed schools at Assalaya locality in White Nile State. Urine samples were exanimated after allowing it to sediment in a conical urinalysis glass. A drop from the sediment is taken and examined under the light microscope for the presence of $S$. hematobium ova and by a filtration method. The percentage of the infection was 154/385 (40\%). The highest frequency of positive cases were found among the age group of 12 to 15 years $91 / 154$ (59.1\%) but no significant association between age distribution and positive results was found ( $p$-value $=$ 0.18 ). In this study no significant association between sex and urinary schistosomiasis was found ( $p$-value $=0.64)$. About $253 / 385(65.7 \%)$ of population know the mode of transmission of the schistosomiasis from infected water with snails transmit the infection. There was significant association between contact to canals and the infection ( $p$-value $<0.05$ ). There was no significant association between father and mother education and the infection ( $p$-values $=0.08,0.06$ respectively), monthly income and the infection ( $p$ value $=0.31)$, the source of water supply and the disease $(p$-value $=0.43$ ). While there was significant association between lack of latrines in houses and the infection ( $p$-value $<0.05)$.
\end{abstract}

Keywords: Urinary schistosomiasis, White Nile State, Sudan, prevalence.

E-mail: mogadam92@gmail.com.

\section{INTRODUCTION}

Schistosomiasis is one of the most common parasitic infections in the world, ranking second after malaria in terms of socio-economic and public health importance, especially in rural areas of developing countries (Senghor et al., 2014). About 239 million people with active Schistosoma infections in 2009 and 85\% lived in sub-
Saharan Africa. Approximately 112 million and 54 million were infected with urinary and intestinal schistosomiasis, respectively. The number of persons at risk of infection is greater than 600 million (Senghor et al., 2014). Schistosomiasis is prevalent in tropical and subtropical areas, especially in poor communities without access to 
safe drinking water and adequate sanitation. At least $90 \%$ of those requiring treatment for schistosomiasis live estimate in Africa (WHO, 2017).

Schistosomiasis is mainly caused by three different species of blood-dwelling fluke worms of the genus Schistosoma namely Schistosoma haematobium (causes urinary schistosomiasis), S. mansoni and $S$. japonicum (both cause intestinal schistosomiasis). Urinary schistosomiasis is characterized by haematuria as a classical sign. It is associated with bladder and ureteral fibrosis, sandy patches in the bladder mucosa and hydronephrosis that are commonly seen in chronic cases while bladder cancer is possible as late stage complication (Sady et al., 2013).

People become infected when larval forms of the parasite released by freshwater snails - penetrate the skin during contact with infested water in the body, the larvae develop into adult schistosomes, adult worms live in the blood vessels where the females release eggs, some of the eggs are passed out of the body in the faeces or urine to continue the parasite's life cycle, others become trapped in body tissues, causing immune reactions and progressive damage to organs (Senghor et al., 2014).

Symptoms of schistosomiasis are caused by the body's reaction to the worms' eggs. Fibrosis of the bladder and ureter, and kidney damage are sometimes diagnosed in advanced cases, Bladder cancer is another possible complication in the later stages (Senghor et al., 2014). In women, urogenital schistosomiasis may present with genital lesions, vaginal bleeding, and pain during sexual intercourse and nodules in the while in men, urogenital schistosomiasis can induce pathology of the seminal vesicles, prostate and other organs (Senghor et al., 2014).

This disease may also have other long-term irreversible consequences, including infertility, the economic and health effects of schistosomiasis are considerable and the disease disables more than it kills, in addition children, schistosomiasis can cause anemia, stunting and a reduced ability to learn, although the effects are usually reversible with treatment (Senghor et al., 2014). Chronic schistosomiasis may affect people's ability to work and in some cases can result in death. Moreover, the number of deaths due to schistosomiasis is difficult to estimate because of hidden pathologies such as liver and kidney failure and bladder cancer). WHO estimates that there are about 20,000 deaths due to schistosomiasis globally each year (Senghor et al., 2014).

Microscopic examination of excreta (stool, urine) is the gold standard diagnostic test but requires the adult worms to be producing eggs; serological tests can diagnose less advanced infections (Gray et al., 2011).

In Sudan, the risk for schistosomiasis is widespread, especially in the major irrigation systems in the Gezira area between the Blue and White Nile Rivers - high prevalence of $S$. mansoni infection in some areas in the
West Equatorial region and both $S$. mansoni and $S$. hematobium are endemic in the Upper Nile region, in this country, 5 million people are infected by schistosomiasis (Deribe et al., 2011).

According to previous reports on schistosomiasis, the overall prevalence of infections with $S$. mansoni, $S$. haematobium, or both among 6,122 children from 27 schools in the White Nile Province were 10.1, 21.4 and $4.5 \%$, respectively (Ismail et al., 2014). The prevalence of $S$. haematobium in the Upper Nile region and South Darfur were 73 and $56.0 \%$, respectively. And the prevalence of $S$. haematobium in the River Nile State and Southern Kordofan State were 1.7 and 23.7\%, respectively, however there was no $S$. mansoni infection. These data show that there was marked geographical variation in the prevalence of Schistosoma spp infection (Ismail et al., 2014).

Schistosomiasis prevalence maps must be did by Process of planning, coordination, and evaluation of control activities (Schur et al., 2011).

Assalya village accommodate one of the main sugar cane schemes in Sudan and constitute an excellent environment for breeding of intermediate host of Schistosoma species (African Biomphalaria and Bulinus). Yet, the published data about the prevalence of the disease in the area is limited. Therefore, this study was conducted to assess the prevalence, knowledge, attitude and practice of responders about the urinary schistosomiasis.

\section{MATERIALS AND METHODS}

\section{Study design and sample size}

A prospective descriptive cross sectional community based study. It was carried out at Assalya village, which is located at the east of the White Nile State, central part of Sudan with total population of 57.437. The study was conducted between the period of July to December 2011 .The study populations were selected from three basic mixed schools which contained 1677 (males 865, females 812) as total number of children. The children referred to 385-urine sample were collected and selected 223 males, 162 females.

A pretested questionnaire was used to collect data about the demographic, socio-economic, behavioral, and personal hygiene. Information was collected from the children via face-to-face interview. A $10 \mathrm{ml}$ of urine samples were collected during 10 am to $2 \mathrm{pm}$ day time from the pupils and Examination of the urine after allowing it to sediment in a conical urinalysis glass. A drop from the sediment is taken and examined under the light microscope for the presence of $S$. hematobium ova by a filtration method (Ismail et al., 2014).

Filtration is carried out with a Millipore Filtration system using a low pressure vacuum pump. The eggs trapped from the whole filter paper (Whatman) then examine under the microscope immediately at low power (Dazo et al., 1991).

\section{Data analysis}

The data were processed using Microsoft Excel version 2007. Frequency tables were interpreted using Statistical Package for 
Social Sciences (SPSS) software computer package.

\section{Ethical considerations}

Prior to conducting the study written consents were taken from authorities in White Nile state, school staff, children and their parents. Children who were infected were given Praziquantel according to weight.

\section{RESULTS}

The study included 385 children; 223 (57.9\%) were males and $162(42.1 \%)$ were females with ratio of $1.4: 1$. The children were divided into three age groups (6-9, 9-12 and 12-15years), representing $8.8,26.8$ and $64.4 \%$, respectively. Of those $154 / 385(40 \%)$, children's urine samples were proved to be positive for $S$. hematobium ova, while $231(60 \%)$ gave negative results (Figure 1 ). The highest frequency of positive cases were found among the age group of $12-15$ years $91 / 154$ (59.1\%) but no significant association between age distribution and positive result was found $(p$-value $=0.18)($ Table 1$)$. In addition, no significant association between sex and infection was found ( $p$-value $=0.64)($ Table 2$)$.

Concerning the knowledge about the mode of disease transmission 253/385 (65.7\%) knew that contact with water infected with snails transmit the infection, but only $4 / 385(1 \%)$ pupils told that drinking of infected water transmit the infection and 128 gave no answer. Among 188 children who have water taps in their houses 79 cases (42\%) gave positive results for ova with no significant association ( $p$-value $=0.43)$. On the other hand, there was significant association ( $p$-value $<0.05$ ) between lack of latrines in houses and positive results for urinary schistosomiasis.

According to monthly income the children families were grouped into three categories (those with less than 500, 500-1000 and more than 1000 SDG), yet no significant association ( $p$-value $=0.33$ ) was found. Although both level of mother and father education gave no significant association in relation to positive diagnosis of urinary schistosomiasis, the mother education had stronger impact with lesser $p$-value ( $p$-value=.059 for mother and $p$-value $=0.84$ for father). Also strong association between practicing swimming in canal and knowledge about mode of transmission was noticed ( $p$-value $<0.05$ ).

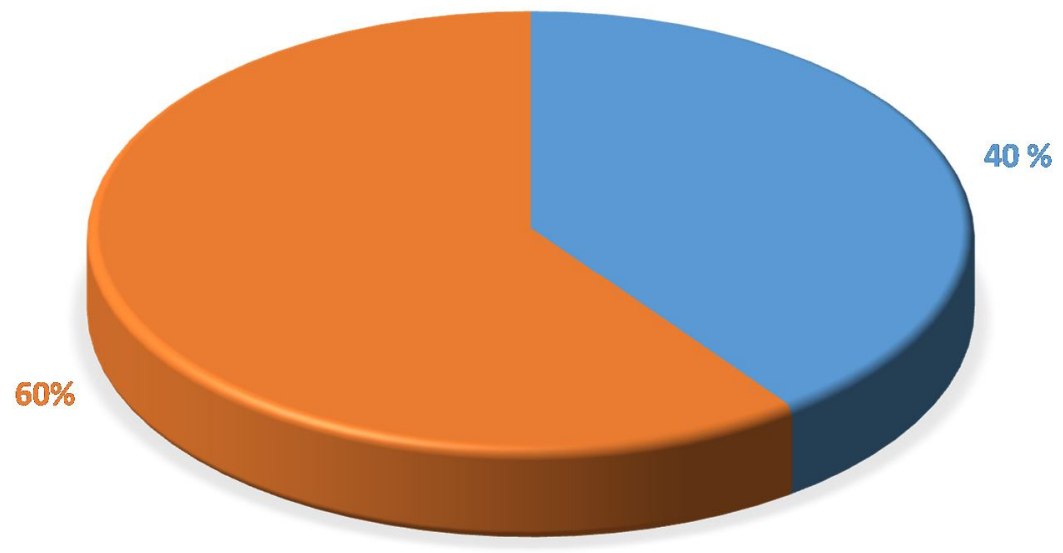

国ositive

negative

Figure 1. Histogram showing the percentage of $S$. hematobium infection.

\section{DISCUSSION}

In this study, the percentage of cases with positive ova was $40 \%$, while in a previous study in the same area done by Abd El-Rahman and Abd-Alla (2011) out of 2034 urine samples $S$. haematobium eggs were seen in 622 (30.58\%) (El-Rahman and Abd-Alla, 2011). This low incidence compared to our study may be attributed to difference in population of studied group because their study involved two sectors, schoolchildren and the population of Combo Village that included adults. In a study done in Senegal, prevalence of urinary schistosomiasis among school children in the Niakhar district was $57.6 \%$ (Senghor et al., 2014). It is slightly raised prevalence compared to our study that may be related to different geographic area. Another study that gave lower prevalence values prevalence values was conducted in middle and Lower Awash Valley, Afar Regional State of Ethiopia; it included school-age children living in the area with overall prevalence of urinary schistosomiasis of $20.8 \%$ (Degarege et al., 2015). In a study done in Yemen, the situation was better with $31.8 \%$ overall prevalence of schistosomiasis; $23.8 \%$ of them were infected with $S$. haematobium and $9.3 \%$ were infected with $S$. mansoni. The high infestation rate of $S$. haematobium in this area compared to $S$. mansoni is due 
Table 1. Relation between age- groups and urinary schistosomiasis infection rate.

\begin{tabular}{lcccc}
\hline \multirow{2}{*}{ Age (years) } & \multicolumn{3}{c}{ Infection rate } & \multirow{2}{*}{ P value } \\
\cline { 2 - 4 } & Positive & Negative & Total & \\
\hline $6-9$ & $17(11.0)$ & 17 & 34 & \\
$9-12$ & $46(29.9)$ & 57 & 103 & 0.18 \\
$12-15$ & $91(59.1)$ & 157 & 248 & \\
Total & $154(100)$ & 231 & 385 & \\
\hline
\end{tabular}

Table 2. Relationship between gender and urinary schistosomiasis infection rate.

\begin{tabular}{lcccc}
\hline \multirow{2}{*}{ Gender } & \multicolumn{3}{c}{ Infection rate } & \multirow{2}{*}{ P value } \\
\cline { 2 - 4 } & Positive & Positive & Total & \\
\hline Male & $87(56.5)$ & 136 & 223 & \multirow{2}{*}{0.64} \\
Female & $67(43.5)$ & 95 & 162 & \\
Total & $154(100)$ & 231 & 385 & \\
\hline
\end{tabular}

to more favourable environmental conditions for the development of the intermediate hosts of these species at the expense of $S$. mansoni. In fact, Saotoing et al. (2011) justified the high infestation rate of $S$. haematobium among populations, which is due to the easy spread of parasite eggs in relation to $S$. mansoni eggs in the stool and which should first undergo its dilution before being scattered.

They also found that prevalence of schistosomiasis was significantly higher among children aged $>10$ years compared to those aged $\leq 10$ years $(P<0.05)$ (Sady et al., 2013). In our study, the highest frequency of positive cases was found among the age group of 12 to 15 years (64.4\%). This agreed also with Senghor et al. (2008), where the highest prevalence values of urinary schistosomiasis were recorded in the 10-12 and 13-15 year groups (Senghor et al., 2014). This variation may be related to this group interested in canals as a site for playing rather than a source for water supply. The increase of prevalence with increasing age of children was also noted in Darfur, Sudan; where the children in the age group 10-14 has the highest infection rate (Deribe et al., 2011). The 12-15 age group would carry out risky activities outside of the classrooms. Certainly, they must actively and regularly take part in the field work and would be more in contact with the water infested with furcucercaires than other age groups. This exposes them to contamination.

This age has more chance to be in contact with canals without close observation from adults and is most likely responsible for transmission of disease in the area. While in our study, no significant association between age distribution and positive result was found ( $\mathrm{p}$-value $=$ 0.18 ). In addition, no significant association between sex and urinary schistosomiasis was found in our study.

This agrees with Ahmed et al. (2012) in central Sudan, who found similar prevalence in boys and girls. In addition, it agrees with the study on Awash Valley Ethiopia where age and sex were not significantly associated with $S$. haematobium infection.

A statistically significant difference was observed where prevalence of $S$. haematobium in males was $38.99 \%$ and in females 22.96\% (El-Rahman and Abd-Alla, 2011). Only $65.7 \%$ had knowledge about the mode of disease transmission. In such endemic area, the knowledge about this disease was expected to be higher than that. In addition, there was significant association between admit practicing swimming in canal and knowledge of mode of transmission ( $p$-value $=0.05$ ). Among those who have water taps in their houses $42 \%$ gave positive results for urinary schistosomiasis which reflected no significant association $p$-value $=0.43$.

The rate monthly income gave no significant association in relation to urinary schistosomiasis positive cases. Although both level of mother and father education gave no significant association in relation to positive diagnosis of urinary schistosomiasis, the mother education had stronger impact with lesser $p$-value ( $p$ value $=0.059$ was for mother and $p$-value $=0.841$ for father). This may reflects stronger role for mothers in the area concerning children education and habits.

\section{Conclusions}

The infection rate for urinary schistosomiasis is still high in the studied area. These results support an urgent need to start an effective schistosomiasis control programme. In addition to drug distribution, health education, community movement and introduction of proper sanitation this may reduce the morbidity caused by schistosomiasis. The public health authorities should also screening, treating other infected children and intensify the protocol for eradication of Urinary schistosomiasis in 
the area.

\section{REFERENCES}

Ahmed, A. M., Abbas, H., Mansour, A. F., Gasim, G., and Adam, I. (2012). Schistosoma haematobium infections among schoolchildren in central Sudan one year after treatment with praziquantel. Parasit Vectors. 5: 108-111.

Dazo, C. B., and Biles, E. J. (1991). Two new field techniques for detection and counting of schistosoma haematobium eggs in urine samples, with an evaluation of both methods. World Health Organization. 1991.

Degarege, A., Mekonnen, Z., Levecke, B., Legesse, M., Negash, Y., Vercruysse, J. B., and Erko, B. (2015). Prevalence of Schistosoma haematobium Infection among School-Age Children in Afar Area, Northeastern Ethiopia. PLoS One, 10(8)

Deribe, K., Eldaw, A., Hadziabduli, S., Kailie, E., Omer, D. M., Mohammed, E. A., Mergani, A., Ali, G. A., Babikir, K., Adem, A., and Hashim, F. (2011). High prevalence of urinary schistosomiasis in two communities in South Darfur: Implication for interventions. Parasit Vectors, 4: 14.

El-Rahman, A., and Abd-Alla, N. A. (2015). The Epidemiology of Two Water-Borne Diseases (Malaria And Schistosomiasis) at Assalya Sugar Cane Scheme, White Nile State, Sudan. Available on: http://khartoumspace.uofk.edu/handle/123456789/13348.

Gray, J. D., Ross, G. A., Li, Y., McManus, P. D. (2011). Diagnosis and management of schistosomiasis. BMJ, 342: d2651.

Ismail, A. H. A. H., Hong, S., Babiker, B. T. A., Hassan, A. M. R., Sulaiman, Z. A. M., Jeong, H., Kong, W. H., Lee, S. H., Cho, H. I., Nam, H. S., Oh, C. H., and Lee, Y.H. (2014). Prevalence, risk factors, and clinical manifestations of schistosomiasis among school children in the White Nile River basin, Sudan. Parasit Vectors, 7: 478.

Sady, H., Al-Mekhlafi, M. H, Mahdy, K. A. M., Lim, L. A. Y., Mahmud, R., and Surin, J. (2013). Prevalence and associated factors of schistosomiasis among children in Yemen: Implications for an effective control programme. PLoS Negl Trop Dis, 7(8).

World Health Orgnization (WHO) (2017). Schistosomiasis. (I citied may 2017). Available on: http://www.who.int/mediacentre/factsheets /fs115/en/.
Schur, N., Hürlimann, E., Garba, A., Traoré, S. M., Ndir, O., Ratard, C. R., Tchuenté, T. L., Kristensen, T. K., Utzinger, J., and Vounatsou, P. (2011). Geostatistical model-based estimates of schistosomiasis prevalence among individuals aged $\leq 20$ years in West Africa. pLoS Negl Trop Dis, 5(6).

Senghor, B., Diallo, A., Sylla, N. S., Doucouré, S., Ndiath, O. H., Gaayeb, L., Djuikwo-Teukeng, F. F., Bâ, C. T., and Sokhna, C., (2014). Prevalence and intensity of urinary schistosomiasis among schoolchildren in the district of Niakhar, region of Fatick, Senegal. Parasit Vectors, 7:5.

Citation: Elsiddig, H. A., Khider, E., Nour, S. M., M akhawi, A. M., and Mogadam, E. B. M. (2019). Prevalence of urinary schistosomiasis among schoolchildren in White Nile State, Sudan. African Educational Research Journal, 7(1): 29-32. 